\title{
Pre-procedural renal resistive index accurately predicts contrast- induced acute kidney injury in patients with preserved renal function submitted to coronary angiography
}

\author{
Maciej T. Wybraniec ${ }^{1,2}$ • Maria Bożentowicz-Wikarek ${ }^{3}$ Jerzy Chudek $^{3}$ • \\ Katarzyna Mizia-Stec ${ }^{1,2}$
}

Received: 13 August 2016 / Accepted: 7 December 2016 / Published online: 19 December 2016

(c) The Author(s) 2016. This article is published with open access at Springerlink.com

\begin{abstract}
The study aimed to evaluate the clinical utility of ultrasonographic intra-renal blood flow parameters, together with the wide range of different risk factors, for the prediction of contrast-induced acute kidney injury (CI$\mathrm{AKI}$ ) in patients with preserved renal function, referred for coronary angiography or percutaneous coronary interventions (CA/PCI). This prospective study covered 95 consecutive patients (69.5\% men; median age 65 years) subject to elective or urgent CA/PCI. Data regarding 128 peri-procedural variables were collected. Ultrasonographic intrarenal blood flow parameters, including renal resistive index (RRI) and pulsatility index (RPI), were acquired directly before the procedure. CI-AKI was defined as $\geq 50 \%$ relative or $\geq 0.3 \mathrm{mg} / \mathrm{dL}$ absolute increase of serum creatinine $48 \mathrm{~h}$ after procedure. CI-AKI was confirmed in nine patients (9.5\%). Patients with CI-AKI had higher SYNTAX score $(\mathrm{p}=0.0002)$, higher rate of left main disease $(\mathrm{p}<0.00001)$, peripheral artery disease $(\mathrm{PAD} ; \mathrm{p}=0.02)$, coronary artery anomaly $(p=0.017)$, more frequently underwent surgical revascularization $(\mathrm{p}=0.0003)$, 'had greater...' intima$(\mathrm{p}=0.004)$ and extra-medial thickness $(\mathrm{p}=0.001)$, and received higher contrast media dose $(p=0.049)$, more often overused non-steroidal anti-inflammatory drugs $(\mathrm{p}=0.001)$, and had substantially higher pre-procedural
\end{abstract}

Maciej T. Wybraniec

wybraniec@os.pl; maciejwybraniec@gmail.com

1 First Department of Cardiology, School of Medicine in Katowice, Medical University of Silesia, 47 Ziołowa St., 40-635 Katowice, Poland

2 Upper Silesia Medical Centre, Public Hospital No. 7, Katowice, Poland

3 Department of Pathophysiology, Medical University of Silesia, Katowice, Poland
RRI (0.69 vs. 0.62; $\mathrm{p}=0.005)$ and RPI values (1.54 vs. $1.36 ; \mathrm{p}=0.017)$. Logistic regression confirmed age, SYNTAX score, presence of PAD, diabetes mellitus, and preprocedural RRI independently predicted CI-AKI onset $(\mathrm{AUC}=0.95 ; \mathrm{p}<0.0001)$. Pre-procedural RRI $>0.69$ had $78 \%$ sensitivity and $81 \%$ specificity in CI-AKI prediction. High pre-procedural RRI seems to be a useful novel risk factor for CI-AKI in patients with preserved renal function. Coronary, peripheral and renal vascular pathology contribute to the development of CI-AKI following CA/PCI.

Keywords Contrast-induced acute kidney injury • CI-AKI $\cdot$ Renal resistive index $\cdot$ RRI $\cdot$ Renal pulsatility index $\cdot$ RPI

\section{Introduction}

Ubiquitous application of contrast media (CM) confers a major risk of contrast induced-acute kidney injury (CI$\mathrm{AKI})$. The rate of this frequently overlooked complication varies from 2.5 to $13.1 \%$ of coronary angiographies and percutaneous coronary interventions (CA/PCI) [1-3] and has been repeatedly linked to increased morbidity and mortality [1, 4]. Given the late serum creatinine concentration (SCr) surge following renal injury and so far unsuccessful search for early diagnostic markers of CI-AKI [5], adequate pre-procedural risk stratification and prevention play strategic role in decreasing the burden of CI-AKI. A wide range of CI-AKI risk factors has so far been established, such as impaired baseline kidney function, volume of CM applied, dehydration, advanced age, diabetes mellitus and atherosclerosis severity $[1-3,6]$. The development of renal injury is believed to be triggered by high osmolality and viscosity of $\mathrm{CM}$, leading to increased renal vascular resistance 
[7] and renal tubular hypoxia, eventually causing tubular cell apoptosis [8]. Preexisting increased vascular stiffness, reflected by high central arterial pulse pressure could facilitate CI-AKI via impaired renal blood flow auto-regulation [9]. The Doppler ultrasound of interlobular and/or arcuate arteries delivers indirect insight into renal hemodynamics. Out of all renal blood flow parameters, only renal resistive index (RRI) has been shown to be clinically useful, primarily in the evaluation of renovascular hypertension [10] or the kidney allograft function [11] or the risk of acute kidney injury (AKI) persistence [12]. Of note, RRI assessed in the setting of intensive care unit (ICU) accurately predicted the development and persistence of AKI [13]. RRI could represent an indicator of diffuse arterial stiffness and cardiovascular risk factor [14], predicting long-term morbidity and mortality [15]. Yet, several factors can interfere with RRI values, including pulse blood pressure, heart rate and rhythm, presence of significant aortic valve stenosis, age, renal interstitial disease or vascular compliance [16]. Also, patients with chronic kidney disease were shown to have an altered and delayed vascular response to contrast media [7].

We thus hypothesized that RRI, after adjustment for its covariates, could serve as an indicator of baseline renal vascular resistance and contribute to CI-AKI risk stratification in patients devoid of preexisting kidney pathology. Accordingly, the purpose of the study was to evaluate the clinical significance of preoperative ultrasonographic parameters of intra-renal blood flow, along with numerous pre- and intra-operative risk factors, for the prediction of CI-AKI in patients with coronary artery disease (CAD) and preserved renal function, referred for elective and urgent coronary angiography.

\section{Methods}

This research represents a prospective observational study, which involved 95 consecutive patients with either stable angina (SA) or non-ST-elevation acute coronary syndrome (NSTE-ACS). All patients were hospitalized in the department of cardiology between 2013 and 2015 and referred for planned or urgent CA/PCI. Patients were enrolled for the study during the initial check-up at hospital, prior to the procedure. The study was conducted in adherence to Declaration of Helsinki Guidelines and was approved by the local Ethics Committee. On admission all patients gave their written informed consent to participation in the research.

Inclusion criteria comprised: (a) stable angina with high pre-test probability of CAD or SA with positive treadmill electrocardiographic stress test or echocardiographic dobutamine test; or (b) non-ST-elevation acute coronary syndrome that met diagnostic criteria as established in ESC NSTE-ACS 2011 guidelines.
Exclusion criteria were as follows: (a) significant hemodynamic instability (cardiogenic shock; Killip class $>2$; systolic blood pressure (SBP) $<90 \mathrm{mmHg}$ or acute decrease by $40 \mathrm{mmHg}$ or catecholamine use dependence); (b) acute or chronic respiratory failure (blood oxygen saturation $<90 \%$ ); (c) severe heart failure with left ventricular ejection fraction (LVEF) <35\%; (d) chronic kidney disease with eGFR $<50 \mathrm{~mL} / \mathrm{min} / 1.73 \mathrm{~m}^{2}$ or proteinuria $>500 \mathrm{mg} / \mathrm{L}$; (e) active urinary tract infection; (f) evidence of renal artery stenosis or hydronephrosis (g) moderate to severe aortic valve stenosis; (h) severe valvular heart disease of any kind; (i) high pulse pressure $>80 \mathrm{mmHg}$; (j) tachycardia $>100 \mathrm{bpm}$ or bradycardia $<50 \mathrm{bpm}$; (k) severe obesity (body mass index, BMI $>40 \mathrm{~kg} / \mathrm{m}^{2}$ ); (l) active neoplastic disease; (m) liver dysfunction (any hepatic aminotransferase $>3 \times$ upper reference limit); (n) intolerance of statin or history of rhabdomyolysis or myositis or (o) age $<18$ or $>80$ years old.

The primary endpoint was the onset of CI-AKI defined according to Acute Kidney Injury Network criteria, namely $\geq 50 \%$ relative or $\geq 0.3 \mathrm{mg} / \mathrm{dL}$ absolute increase of serum creatinine concentration (SCr) at $48 \mathrm{~h}$ after procedure [17]. Data regarding 128 pre- and intra-procedural variables were collected in all study participants and compared between CI-AKI and non-CI-AKI group. Patients were meticulously interviewed and former discharge summaries were revised in order to collect demographic and comorbidities data. The list of all current medications was obtained. Routine laboratory tests and anthropometric measurements, and baseline echocardiographic study and carotid artery scans were performed on admission in all study participants.

Blood samples were collected from antecubital or radial vein at admission, 24 and $48 \mathrm{~h}$ following CA. Baseline standard laboratory panel, including serum creatinine concentration ( $\mathrm{SCr}$ ) was evaluated at admission, while 24-h and 48-h blood samples were assayed only for SCr.

Ultrasonographic indices of intra-renal blood flow in arcuate/interlobular arteries were assessed directly before and $1 \mathrm{~h}$ after the procedure. The renal Doppler ultrasound was performed by one experienced physician using Vivid 7 (GE Healthcare) with a 5C probe $(4.4-6.7 \mathrm{MHz})$ designed for high-frequency vascular applications within abdominal cavity. The study was performed on patients in supine position, after $10 \mathrm{~min}$ of rest and prior blood pressure measurement. Initially, length and width of renal artery was determined and main renal artery stenosis was excluded by means of peak systolic and end-diastolic flow velocity calculation.

Subsequently, ultrasonographic parameters of renal blood flow in arcuate/interlobular arteries, located on the border of renal cortex and core were evaluated using a 2-4 mm pulse-wave Doppler gate. Intra-renal blood flow velocity was assessed using the smallest scale allowing 
for precise measurements without the aliasing phenomenon (pulse repetition frequency), but with the highest possible gain and the lowest possible value of wall motion filter. The Doppler intra-renal blood flow parameters comprised peak systolic (PSV) and end-diastolic velocity (EDV), augmentation index (AI), acceleration time (AT), and further derivatives, including renal resistive index (RRI) and pulsatility index (RPI). RRI was defined as $\mathrm{RRI}=(\mathrm{PSV}-\mathrm{EDV}) / \mathrm{PSV}$, while RPI was defined as: $\mathrm{RPI}=(\mathrm{PSV}-\mathrm{EDV}) / \mathrm{MV}$, where MV stands for mean flow velocity. Renal to abdominal aorta flow velocity ratio (RAR) was calculated as the ratio of arithmetic mean of PSV in main renal arteries and PSV in abdominal aorta. The measurements were performed three times for each kidney during pre-procedural evaluation on different intra-renal arteries (upper, mid and lower lobe of kidney). The final result represented an arithmetic mean of three blood flow scans of right and left kidney (six measurements for pre-procedural evaluation). The intra-observer variability was $96 \%$ for RRI and $91 \%$ for RPI. The duration of the bilateral renal Doppler ultrasound was approximately 5-10 min.

Echocardiographic check-up was conducted using Vivid 7 (GE Healthcare) with a $2.5-\mathrm{MHz}$ probe by a single investigator. Subsequently, carotid scans were performed using a Logic 7, GE ultrasound machine with a 7-12-MHz linear array transducer and then analyzed using quantitative analysis package (Siemens) characterized by an axial resolution of $0.001 \mathrm{~mm}$.

All the study participants received standard prophylaxis of CI-AKI. Only low-osmolar and iso-osmolar CM at the lowest possible dose was used in all study participants. $\mathrm{CA}$ and PCI were performed by five different experienced interventional cardiologists. All the patients with moderately impaired kidney function (eGFR $50-60 \mathrm{~mL} / \mathrm{min}$ ) received an IV infusion of $0.9 \%$ saline at a rate of $1 \mathrm{~mL} /$ $\mathrm{kg} / \mathrm{h}$ starting from $12 \mathrm{~h}$ before to 24 after CA. Patients with eGFR $>60 \mathrm{~mL} / \mathrm{min}$ only obtained a single infusion of $500 \mathrm{~mL} 0.9 \%$ saline prior to procedure.

HTN was diagnosed if blood pressure exceeded $140 / 90 \mathrm{mmHg}$ on two separate measurements during index hospitalization or in the event of former HTN diagnosis or antihypertensive medication use. Diabetes mellitus / impaired fasting glucose/impaired glucose tolerance were analyzed jointly. DM was diagnosed if fasting blood glucose was $>125 \mathrm{mg} / \mathrm{dL}$ on two separate days or if patients received insulin or oral hypoglycemic agents. Non-steroidal anti-inflammatory drugs (NSAID) use was defined $>1$ dose/per week use of NSAIDs. The pre-procedural risk of CI-AKI development was additionally estimated based on Mehran et al. risk score [2]. Hypotension during procedure was defined as the sudden decrease of invasively monitored SBP below $90 \mathrm{mmHg}$ or by more than $40 \mathrm{mmHg}$.
The coronary anatomy and morphology of coronary lesions were assessed by an experienced interventional cardiologist. The SYNTAX score was calculated using widely accessible online calculator.

Statistical analysis was performed using MedCalc v.14.8.1 software (MedCalc Software, Ostend, Belgium). Quantitative variables were presented as the mean value \pm standard deviation (SD) or median (boundaries of 25 and 75 percentile) and qualitative parameters were expressed as number and percentage. The type of distribution was verified using Shapiro-Wilk test. In case of normally-distributed variables, Student's $t$ test for unpaired samples was used, while Mann-Whitney $U$ test was implemented in non-normally distributed parameters. Qualitative variables were compared using the Pearson's Chi square test. Initially all CI-AKI predictor variables were evaluated in univariate analysis and odds ratios (OR) with 95\% confidence interval (CI) were calculated. All the variables with $\mathrm{p}<0.1$ in univariate model were incorporated into the logistic regression analysis model. The area under (AUC) receiver operating characteristic (ROC) curve for the model was calculated. Optimum cut-off point of pre-procedural renal blood flow parameters were established using Youden's J statistic estimation. In order to determine the relationship between variables, the Pearson's and Spearman coefficient of correlation were calculated. A ' $p$ ' value of less than 0.05 was regarded as statistically significant.

\section{Results}

The study involved 95 consecutive patients referred for elective or urgent coronary angiography. Demographic and clinical characteristics are highlighted in Table 1. No gender-based differences were observed. The majority of study participants were diagnosed with non-ST-elevation acute coronary syndrome $(\mathrm{n}=54,56.8 \%)$ and stable angina was slightly less frequent $(n=41 ; 43.2 \%)$. The vast majority of study participants received angiotensin-converting enzyme inhibitors $(\mathrm{n}=84,88.4 \%)$, beta-blockers $(\mathrm{n}=80,84.2 \%)$, statins $(n=84,88.4 \%)$. Considerably smaller proportion of patients was treated with calcium channel blockers $(n=26$, 27.4\%), mineralocorticoid receptor antagonists $(n=16$, $16.8 \%)$, loop or thiazide diuretics $(n=28,29.5 \%)$, nitrates $(\mathrm{n}=19,20 \%)$, metformin $(\mathrm{n}=16,16.8 \%)$, trimetazidine $(\mathrm{n}=11,11.6 \%)$ and allopurinol $(\mathrm{n}=7,7.4 \%)$. Thirteen patients $(13.7 \%)$ overused non-steroidal anti-inflammatory drugs. The median hospitalization time was $4(3 ; 4)$ days. The general Doppler parameters of renal and intra-renal blood flow are presented in Table 2.

Following coronary angiography, $44.2 \%(n=42)$ of patients were referred for direct PCI, while $14.7 \%(n=14)$ required elective or urgent coronary artery bypass grafting 
Table 1 Demographic and clinical characteristics of the study population

\begin{tabular}{|c|c|}
\hline Variable & $\begin{array}{l}\mathrm{N}=95 \text { absolute count }(\%) \text { or } \\
\text { median }(25-75 \text { percentile }) \text { or } \\
\text { mean } \pm \mathrm{SD}\end{array}$ \\
\hline Age (years) & $65(59 ; 71)$ \\
\hline Men & $66(69.5 \%)$ \\
\hline Body mass index $\left(\mathrm{kg} / \mathrm{m}^{2}\right)$ & $28.4(25.9 ; 32.3)$ \\
\hline Obesity & $39(41.1 \%)$ \\
\hline Waist-to-hip ratio & $1.01(0.96 ; 1.08)$ \\
\hline Cigarette smoking & $58(61.1 \%)$ \\
\hline Acute coronary syndrome & $54(56.3 \%)$ \\
\hline Non-ST-elevation myocardial infarction & $28(29.5 \%)$ \\
\hline Mehran's CI-AKI risk (\%) & $7.5(7.5 ; 14.0)$ \\
\hline SYNTAX score (pts) & $12(4 ; 25)$ \\
\hline Left main disease & $10(10.5 \%)$ \\
\hline Arterial hypertension & $91(95.8 \%)$ \\
\hline DM/IFG/IGT & $37(38.5 \%)$ \\
\hline Dyslipidemia & $88(92.6 \%)$ \\
\hline Atrial fibrillation (paroxysmal/persistent) & $21(22.1 \%)$ \\
\hline Peripheral artery disease & $16(16.8 \%)$ \\
\hline Chronic obstructive pulmonary disease & $9(9.5 \%)$ \\
\hline History of myocardial infarction & $41(43.2 \%)$ \\
\hline History of stroke/transient ischemic attack & $7(7.4 \%)$ \\
\hline Heart rate $(\mathrm{bpm})$ & $64(57 ; 75)$ \\
\hline Systolic blood pressure (mmHg) & $135(120 ; 145)$ \\
\hline Diastolic blood pressure $(\mathrm{mmHg})$ & $80(70 ; 90)$ \\
\hline Pulse blood pressure (mmHg) & $60(50 ; 70)$ \\
\hline Left ventricular ejection fraction (\%) & $55(50 ; 60)$ \\
\hline $\mathrm{E} / \mathrm{e}^{\prime}$ & $8.6(6.7 ; 12.1)$ \\
\hline Mitral valve insufficiency (mild-moderate) & $61(63.5 \%)$ \\
\hline Left atrium diameter $(\mathrm{mm})$ & $40(36 ; 43)$ \\
\hline Left ventricular mass index $\left(\mathrm{g} / \mathrm{m}^{2}\right)$ & $102(90 ; 119)$ \\
\hline Intima-media thickness (mm) & $0.09 \pm 0.03$ \\
\hline Extra-medial thickness (mm) & $0.07(0.05 ; 0.08)$ \\
\hline High sensitivity troponin $\mathrm{T}(\mathrm{ng} / \mathrm{mL})^{\mathrm{a}}$ & $0.02(0.01 ; 0.03)$ \\
\hline Hemoglobin (g/dL) & $13.9 \pm 1.2$ \\
\hline White blood cell count $\left(1000 / \mathrm{mm}^{3}\right)$ & $6.9(5.7 ; 7.9)$ \\
\hline Platelet count $\left(1000 / \mathrm{mm}^{3}\right)$ & $197(175 ; 253)$ \\
\hline Alanine transferase (IU/L) & $20(16 ; 29)$ \\
\hline Fasting glucose (mg/dL) & $95(88 ; 111)$ \\
\hline Total cholesterol (mg/dL) & $152.7 \pm 29.1$ \\
\hline Urine specific gravity & $1.02(1.01 ; 1.02)$ \\
\hline SCr-baseline (mg/dL) & $0.93(0.79 ; 1.13)$ \\
\hline Baseline eGFR by MDRD (mL/min/1.73 m²) & $80.7 \pm 20.8$ \\
\hline
\end{tabular}

CI-AKI contrast-induced acute kidney injury, DM/IFG/IGT diabetes mellitus/impaired fasting glucose/ impaired glucose tolerance, $S C r$ serum creatinine concentration, $e G F R$ estimated glomerular filtration rate

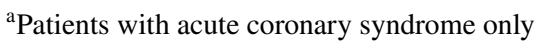

(CABG). Operators predominantly used femoral access, while radial approach was chosen only in $18.8 \%$ of cases $(\mathrm{n}=18)$. The median duration of the procedure was $36 \mathrm{~min}$. (25; 50). Drug-eluting stents were used exclusively in all study participants qualified for PCI. No patients required intra-aortic balloon pump use during the peri- and postprocedural period. Transient period of intra-procedural hypotension occurred in five patients (5.3\%). Fractional flow reserve and intravascular ultrasound were utilized in only one patient respectively $(1.1 \%)$. 
Table 2 Pre-procedural renal Doppler ultrasound

\begin{tabular}{ll}
\hline Variable & $\begin{array}{l}\mathrm{N}=95 \text { absolute count }(\%) \text { or } \\
\text { median }(25-75 \text { percentile) or } \\
\text { mean } \pm \mathrm{SD}\end{array}$ \\
\hline Abdominal Ao $\mathrm{V}_{\max }(\mathrm{m} / \mathrm{s})$ & $0.59 \pm 0.13$ \\
PSV_renal artery $(\mathrm{m} / \mathrm{s})$ & $0.64 \pm 0.12$ \\
EDV_renal artery $(\mathrm{m} / \mathrm{s})$ & $0.26(0.23 ; 0.29)$ \\
RAR & $1.06(0.91 ; 1.23)$ \\
PSV_intra-renal $(\mathrm{m} / \mathrm{s})$ & $0.42 \pm 0.096$ \\
EDV_intra-renal $(\mathrm{m} / \mathrm{s})$ & $0.16 \pm 0.05$ \\
Renal resistive index & $0.63 \pm 0.07$ \\
Renal pulsatility index & $1.38 \pm 0.22$ \\
Renal AT $(\mathrm{m} / \mathrm{s})$ & $59.0(51.0 ; 70.0)$ \\
Renal AI $\left(\mathrm{m} / \mathrm{s}^{2}\right)$ & $4.1(3.6 ; 4.6)$
\end{tabular}

$P S V$ peak systolic velocity, $E D V$ end-diastolic velocity, $A T$ acceleration time, $A I$ acceleration index, $A o$ aorta, $V_{\max }$ maximal velocity, $R A R$ renal-aortic flow velocity index

During the procedure merely low-osmolar (iopromide or iomeprol; $\mathrm{n}=84,88.4 \%$ ) or iso-osmolar CM (iodixanol; $\mathrm{n}=10,10.53 \%$ ) were utilized. The median volume of administered CM was $100 \mathrm{~mL}(80 ; 180)$. The volume of $\mathrm{CM}$ to weight ratio was equal to $1.27 \mathrm{~mL} / \mathrm{kg}(0.85 ; 2.25)$, and the volume adjusted to creatinine clearance was 1.47 $(0.82 ; 2.20)$.

The CI-AKI defined by AKI Network criteria occurred in nine patients (9.5\%). The median $\mathrm{SCr}$ at $24 \mathrm{~h}$ after CA/PCI was $0.96(0.79 ; 1.17) \mathrm{mg} / \mathrm{dL}$, while at $48 \mathrm{~h} \mathrm{SCr}$ amounted to $1.01(0.81 ; 1.20) \mathrm{mg} / \mathrm{dL}$. Seven patients suffered from mild stage $1 \mathrm{AKI}$, defined by relative 1.5-2-fold $\mathrm{SCr}$ increase, whereas two subjects exhibited more severe AKI at stage 2 with 2-3-fold relative $\mathrm{SCr}$ increase. None of the study participants required dialysis therapy. Local vascular complications were reported in 11 patients $(11.6 \%)$. No deaths occurred during the index hospitalization.

Data regarding inter-group differences of qualitative and quantitative parameters are denoted in Tables 3 and 4 respectively. Patients with CI-AKI were characterized by substantially higher pre-procedural RRI ( 0.69 vs. 0.62 ; $\mathrm{p}=0.005)$ and RPI values (1.54 vs. $1.36 ; \mathrm{p}=0.017)$. There was a trend towards lower intra-renal EDV in patients with onset of CI-AKI $(0.13 \pm 0.04$ vs. $0.16 \pm 0.05 \mathrm{~m} / \mathrm{s}$, $\mathrm{p}=0.089)$, while intra-renal PSV was almost identical in both groups $(0.42 \pm 0.1$ vs. $0.42 \pm 0.1 ; p=0.98)$. Intra-renal AT and AI, as well as RAR and main renal artery PSV and EDV did not differ between CI-AKI and non-CI-AKI group (Table 4).

The results of the univariate analysis are presented in Table 5. Logistic regression analysis confirmed that SYNTAX score $(\mathrm{OR}=1.19$ per 1 pt, 95\% CI 1.061-1.351, $\mathrm{p}=0.0035)$ and pre-procedural $\mathrm{RRI}$ value $(\mathrm{OR}=1.26$ per $0.01,95 \%$ CI $1.036-1.545, \mathrm{p}=0.021)$ were the strongest independent predictors of CI-AKI development. In addition, older age $(\mathrm{OR}=1.19$ per 1 year; $95 \% \mathrm{CI}$ $1.0002-1.433, \mathrm{p}=0.049)$, the presence of peripheral artery disease $(\mathrm{PAD} ; \mathrm{OR}=14.3,95 \% \mathrm{CI} 1.1-230.6, \mathrm{p}=0.045)$ and diabetes mellitus $(\mathrm{OR}=20.5$; 95\% CI 1.01-600.54, $\mathrm{p}=0.048$ ) also heralded the onset of CI-AKI. The area under the receiver operating characteristic curve (Fig. 1) for the model was 0.95 (95\% CI 0.88-0.98; p < 0.0001; Hosmer-Lemeshow goodness of fit $\mathrm{p}=0.51$ ).

The ROC curve analysis revealed that pre-procedural RRI had high predictive power for CI-AKI prediction (AUC $=0.75,95 \%$ CI $0.65-0.83 ; \mathrm{p}=0.03$ ). The threshold value of RRI $>0.69$, associated with the calculated Youden's J statistic, had sensitivity of $78 \%$, specificity of $81 \%$, positive likelihood ratio of 4.18 (95\% CI 2.4-7.3), negative likelihood ratio of 0.27 (95\% CI 0.08-0.9) for CIAKI prediction (Fig. 2).

The analysis of correlation revealed that both pre-procedural RRI ( $r=0.24, p=0.02$; Fig. 3$)$ and RPI $(r=0.20$, $\mathrm{p}=0.0497)$ positively correlated with $\mathrm{SCr}$ at $48 \mathrm{~h}$, but not with the baseline SCr (RRI: $r=0.15, p=0.14$; RPI: $r=0.09$, $\mathrm{p}=0.36$ ) and eGFR (RRI: $\mathrm{r}=-0.03, \mathrm{p}=0.72$; RPI: $\mathrm{r}=0.09$, $\mathrm{p}=0.34)$. Also, there was a statistical trend towards a positive correlation between RRI and SYNTAX score $(r=0.18$, $\mathrm{p}=0.07)$, and towards negative correlation between RRI and LVEF ( $\mathrm{r}=-0.18, \mathrm{p}=0.07$ ). Moreover, RRI positively corresponded with waist-to-hip ratio $(\mathrm{r}=0.23, \mathrm{p}=0.02)$. SYNTAX score positively correlated with both total and weight-adjusted volume of $\mathrm{CM}(\mathrm{r}=0.58, \mathrm{p}<0.0001$ and $\mathrm{r}=0.58, \mathrm{p}<0.0001)$, as well as with IMT $(\mathrm{r}=0.72$, $\mathrm{p}<0.0001)$ and EMT $(\mathrm{r}=0.56, \mathrm{p}<0.0001)$.

\section{Discussion}

This prospective study was designed to investigate into the pre- and intra-procedural risk factors of CI-AKI in subjects with stable angina or acute coronary syndromes, but without preexisting renal function impairment, who were referred for planned or urgent coronary angiography. Special consideration was given to baseline intra-renal blood flow parameters. The present study corroborated the significance of widespread vascular pathology in the prediction of CI-AKI in the setting of cardiology department. CAD severity reflected by SYNTAX score and the presence of PAD were found to be key predictors of CI-AKI in patients with preserved renal function, while renal vascular abnormalities further enhanced the predictive power of the model.

Our study constitutes, by far, the first report in literature showing successful application of RRI as a pre-procedural predictor of CI-AKI. According to present findings, baseline RRI and RPI values were significantly higher among 
Table 3 Comparison of CI-AKI and non-CI-AKI group in terms of different qualitative risk factors

\begin{tabular}{|c|c|c|c|}
\hline Variable & $\begin{array}{l}\mathrm{N}=86 \\
\mathrm{CI}-\mathrm{AKI} \text { AKIN (-) } \\
\mathrm{n}(\%)\end{array}$ & $\begin{array}{l}\mathrm{N}=9 \\
\mathrm{CI}-\mathrm{AKI} \text { AKIN (+) } \\
\mathrm{n}(\%)\end{array}$ & $\mathrm{p}^{*}$ \\
\hline Men & $58(67.4 \%)$ & $8(88.9 \%)$ & 0.184 \\
\hline Obesity & $35(40.7 \%)$ & $4(44.4 \%)$ & 0.828 \\
\hline Cigarette smoking & $52(60.5 \%)$ & $6(66.7 \%)$ & 0.716 \\
\hline hsTnT-positive & $25(29.1 \%)$ & $3(33.3 \%)$ & 0.347 \\
\hline ACS (UA or NSTEMI) & $47(54.7 \%)$ & $7(77.8 \%)$ & 0.183 \\
\hline History of acute kidney injury & $4(4.7 \%)$ & $1(11.1 \%)$ & 0.398 \\
\hline History of myocardial infarction & $35(40.7 \%)$ & $6(66.7 \%)$ & 0.135 \\
\hline Peripheral artery disease & $12(13.9 \%)$ & $4(44.4 \%)$ & 0.020 \\
\hline Arterial hypertension & $82(95.3 \%)$ & $9(100.0 \%)$ & 0.509 \\
\hline Atrial fibrillation & $20(23.3 \%)$ & $1(11.1 \%)$ & 0.403 \\
\hline Dyslipidemia & $79(91.9 \%)$ & $9(100 \%)$ & 0.374 \\
\hline DM/IFG/IGT & $31(36.0 \%)$ & $6(66.7 \%)$ & 0.073 \\
\hline Mild proteinuria & $8(9.4 \%)$ & $1(11.1 \%)$ & 0.869 \\
\hline Chronic obstructive pulmonary disease & $8(9.3 \%)$ & $1(11.1 \%)$ & 0.860 \\
\hline Radial vascular access & $17(19.8 \%)$ & $1(11.1 \%)$ & 0.528 \\
\hline Coronary artery anomaly & $3(3.5 \%)$ & $2(22.2 \%)$ & 0.017 \\
\hline Left main disease & $5(5.8 \%)$ & $5(55.6 \%)$ & $<0.0001$ \\
\hline SYNTAX score $>32$ pts & $4(4.7 \%)$ & $6(66.7 \%)$ & $<0.0001$ \\
\hline Referral for $\mathrm{CABG}$ & $9(10.5 \%)$ & $5(55.6 \%)$ & 0.0003 \\
\hline Iso-osmolar contrast media & $8(9.3 \%)$ & $2(22.2 \%)$ & 0.229 \\
\hline Time of procedure: $6 \mathrm{am}-$ noon & $43(50.0 \%)$ & $1(11.1 \%)$ & 0.026 \\
\hline Time of procedure: noon $-6 \mathrm{pm}$ & $30(34.9 \%)$ & $6(66.7 \%)$ & 0.062 \\
\hline PCI ad hoc & $38(44.2 \%)$ & $4(44.4 \%)$ & 0.988 \\
\hline Hypotension during procedure & $4(4.6 \%)$ & $1(11.1 \%)$ & 0.409 \\
\hline Mitral valve insufficiency (mild-moderate) & $56(65.1 \%)$ & $5(55.6 \%)$ & 0.569 \\
\hline Regional wall motion abnormalities & $45(52.3 \%)$ & $7(77.8 \%)$ & 0.144 \\
\hline LVEF $<50 \%$ & $21(24.4 \%)$ & $3(33.3 \%)$ & 0.558 \\
\hline $\mathrm{E} / \mathrm{e}^{\prime} \geq 12$ & $20(23.3 \%)$ & $2(22.2 \%)$ & 0.930 \\
\hline Statin therapy prior to contrast exposure & $75(87.2 \%)$ & $9(100.0 \%)$ & 0.254 \\
\hline NSAIDs & $8(9.3 \%)$ & $5(55.6 \%)$ & 0.001 \\
\hline
\end{tabular}

$A C S$ acute coronary syndrome, $U A$ unstable angina, NSTEMI non-ST-elevation myocardial infarction, $I F G$ impaired fasting glucose, $I G T$ impaired glucose tolerance, $P C I$ percutaneous coronary intervention, NSAID non-steroidal anti-inflammatory drug, $A C E I / A R B$ angiotensin converting enzyme inhibitor/angiotensin receptor blocker, $L V E F$ left ventricular ejection fraction

*Pearson's $\mathrm{Chi}^{2}$ test subjects who exhibited CI-AKI following CA/PCI, in comparison to the rest of study participants. This inter-group difference was primarily conditioned by a trend towards lower intra-renal EDV among CI-AKI group. Although, both RRI and RPI constituted predictors of CI-AKI in univariate analysis, the multivariate model indicated that only RRI remained an independent predictor of CI-AKI onset from among all Doppler intra-renal flow indices. Similar findings, but in the setting of ICU, were obtained by Schnell and coworkers [13]. In this study, RRI assessed within $12 \mathrm{~h}$ after admission among ICU patients, was significantly higher in patients with stage 2 or $3 \mathrm{AKI}$, as compared to patients with AKI at stage 0 or 1 (RRI 0.80 vs. 0.66, $\mathrm{p}<0.0001)$ [13]. Most importantly, RRI $>0.71$ acquired within $12 \mathrm{~h}$ following admission was the only parameter predictive of AKI at stage 2 or 3 and outperformed serum and urinary cystatin C [13]. Correspondingly, our results support a similar predictive RRI threshold of 0.69 , yet established before $\mathrm{CM}$ administration. High sensitivity of $78 \%$ and specificity of $81 \%$ for CI-AKI prediction at $48 \mathrm{~h}$, suggest a possible application of RRI during initial checkup, e.g. concurrently with transthoracic echocardiography, for the risk stratification of CI-AKI onset.

The increased RRI value in our study was mainly conditioned by the tendency towards lower intra-renal EDV among patients who developed CI-AKI. We may speculate 
Table 4 Difference between CI-AKI and non-CI-AKI group in terms of different quantitative parameters

\begin{tabular}{|c|c|c|c|}
\hline Variable & $\begin{array}{l}\text { CI-AKI }(-) ; \mathrm{N}=86 \text { median }(25-75 \\
\text { percentile }) \text { or mean } \pm \mathrm{SD}\end{array}$ & $\begin{array}{l}\text { CI-AKI }(+) ; \mathrm{N}=9 \text { median }(25-75 \\
\text { percentile }) \text { or mean } \pm \mathrm{SD}\end{array}$ & $\mathrm{p}$ \\
\hline Age (years) & $65(57 ; 70)$ & $69(62 ; 74)$ & $0.108^{\mathrm{a}}$ \\
\hline BMI $\left(\mathrm{kg} / \mathrm{m}^{2}\right)$ & $28.4(26.4 ; 32.0)$ & $24.5(24.1 ; 33.2)$ & $0.381^{\mathrm{a}}$ \\
\hline Pulse BP (mmHg) & $60(50 ; 70)$ & $50(40 ; 70)$ & $0.492^{\mathrm{a}}$ \\
\hline SYNTAX score (pts) & $11(4 ; 22)$ & $36(25 ; 42)$ & $0.0002^{\mathrm{a}}$ \\
\hline Volume of contrast (mL) & $100(70 ; 160)$ & $120(100 ; 300)$ & $0.049^{\mathrm{a}}$ \\
\hline Volume of contrast/weight $(\mathrm{mL} / \mathrm{kg})$ & $1.20(0.81 ; 2.11)$ & $1.43(1.28 ; 4.11)$ & $0.031^{\mathrm{a}}$ \\
\hline LVEF $(\%)$ & $55(50 ; 60)$ & $50(50 ; 55)$ & $0.297^{\mathrm{a}}$ \\
\hline $\mathrm{E} / \mathrm{e}^{\prime}$ & $8.6(6.7 ; 12.1)$ & $7.1(5.7 ; 8.9)$ & $0.389^{\mathrm{a}}$ \\
\hline $\operatorname{LVMI}\left(\mathrm{g} / \mathrm{m}^{2}\right)$ & $102(91 ; 120)$ & $99(86 ; 112)$ & $0.425^{\mathrm{a}}$ \\
\hline IMT (mm) & $0.09 \pm 0.026$ & $0.12 \pm 0.04$ & $0.004^{\mathrm{b}}$ \\
\hline EMT (mm) & $0.06(0.05 ; 0.08)$ & $0.09(0.08 ; 0.10)$ & $0.001^{\mathrm{a}}$ \\
\hline hsTnT (ng/mL) & $0.02(0.01 ; 0.04)$ & $0.01(0.01 ; 0.03)$ & $0.549^{\mathrm{a}}$ \\
\hline Hemoglobin (g/dL) & $13.96 \pm 1.192$ & $13.30 \pm 1.48$ & $0.123^{\mathrm{b}}$ \\
\hline ALT (IU/L) & $20(16 ; 29)$ & $16(13 ; 22)$ & $0.051^{\mathrm{a}}$ \\
\hline Fasting glucose (mg/dL) & $95(86 ; 111)$ & $105(95 ; 111)$ & $0.161^{\mathrm{a}}$ \\
\hline Baseline $\mathrm{SCr}(\mathrm{mg} / \mathrm{dL})$ & $0.93(0.79 ; 1.12)$ & $1.02(0.80 ; 1.13)$ & $0.879^{\mathrm{a}}$ \\
\hline Baseline eGFR by MDRD $\left(\mathrm{mL} / \mathrm{min} / \mathrm{m}^{2}\right)$ & $80.32 \pm 19.99$ & $83.79 \pm 29.08$ & $0.637^{\mathrm{b}}$ \\
\hline QTc interval (ms) & $420(400 ; 440)$ & $440(427.5 ; 455)$ & $0.087^{\mathrm{a}}$ \\
\hline Abdominal Ao Vmax (m/s) & $0.60 \pm 0.13$ & $0.52 \pm 0.15$ & $0.108^{\mathrm{b}}$ \\
\hline PSV renal artery $(\mathrm{m} / \mathrm{s})$ & $0.64 \pm 0.12$ & $0.62 \pm 0.10$ & $0.667^{\mathrm{b}}$ \\
\hline EDV renal artery $(\mathrm{m} / \mathrm{s})$ & $0.26(0.23 ; 0.30)$ & $0.28(0.23 ; 0.30)$ & $0.763^{\mathrm{a}}$ \\
\hline RAR & $1.06(0.91 ; 1.29)$ & $1.09(1.02 ; 1.54)$ & $0.239^{\mathrm{a}}$ \\
\hline PSV intra-renal (m/s) & $0.42 \pm 0.10$ & $0.42 \pm 0.09$ & $0.984^{\mathrm{b}}$ \\
\hline EDV intra-renal (m/s) & $0.16 \pm 0.05$ & $0.13 \pm 0.04$ & $0.089^{\mathrm{b}}$ \\
\hline RRI & $0.62 \pm 0.06$ & $0.69 \pm 0.083$ & $0.005^{\mathrm{b}}$ \\
\hline RPI & $1.37(1.24 ; 1.49)$ & $1.52(1.48 ; 1.63)$ & $0.017^{\mathrm{a}}$ \\
\hline Renal AT (ms) & $57.3(50.5 ; 70.0)$ & $68.0(61.0 ; 69.5)$ & $0.384^{\mathrm{a}}$ \\
\hline $\operatorname{Renal} \mathrm{AI}\left(\mathrm{m} / \mathrm{s}^{2}\right)$ & $4.10(3.60 ; 4.60)$ & $4.05(3.85 ; 4.85)$ & $0.712^{\mathrm{a}}$ \\
\hline
\end{tabular}

$B M I$ body mass index, $P S V$ peak systolic velocity, $E D V$ end-diastolic velocity, $A T$ acceleration time, $A I$ acceleration index, $A o$ aorta, $V_{\text {max }}$ maximal velocity, $R A R$ renal-aortic flow velocity index, $A L T$ alanine tranferase, $L V E F$ left ventricular ejection fraction, $P W T$ posterior wall thickness, $I M T$ intima-media thickness, EMT extra-medial thickness, $h s T n T$ high-sensitivity troponin T, TDI tissue Doppler imaging

${ }^{\text {a} M a n n-W h i t n e y ~} U$ test

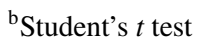

that greater RRI values reflect increased intra-renal vascular resistance related with endothelial dysfunction [8] or possibly renal arteriosclerosis. This baseline augmented intra-renal vascular resistance may act permissive to the tubular injury caused by highly concentrated viscous CM in renal outer medulla [18]. Contrast media cause an imbalance between vasodilative [19] and vasoconstrictive agents [20]. The vasoconstriction of afferent arteriole via adenosine triggered by contrast-induced overstimulation of tubuloglomerular feedback may also contribute to increased renal vascular resistance [21]. All these observations are line with the observed propensity towards increased RRI in subjects exhibiting CI-AKI. Last but not least, invasive measurement of intra-renal blood flow directly before and after CM administration revealed a significant increase of resistance index (defined as ratio of mean blood pressure and average peak renal velocity) and decrease of peak systolic velocity [7].

It is vital to note that, apart from renal vascular resistance, RRI is determined by several other parameters, including pulse and mean arterial pressure [22], heart rate and rhythm [23], blood oxygen saturation [24], renal vascular compliance and renal interstitial fibrosis [16]. Still, almost all these parameters might individually be associated with the risk of CI-AKI development. In the study by Huang et al. based on 448 patients subject to PCI, elevated baseline central pulse pressure was an independent predictor of CI-AKI [9]. Our results did not reveal significant correlation between RRI and pulse, nor systolic or diastolic blood pressure or heart rate, which 
Table 5 Univariate analysis of different pre- and peri-procedural risk factors of CI-AKI

\begin{tabular}{|c|c|c|c|}
\hline Variable & OR & $95 \% \mathrm{CI}$ & $\mathrm{p}$ \\
\hline Age (per 1 year) & 1.09 & $0.99-1.20$ & 0.091 \\
\hline Acute coronary syndrome & 2.91 & $0.56-15.11$ & 0.199 \\
\hline $\begin{array}{l}\text { Hospitalization time (per } 1 \\
\text { day) }\end{array}$ & 1.37 & $0.97-1.94$ & 0.076 \\
\hline Peripheral artery disease & 4.93 & $1.14-21.42$ & 0.033 \\
\hline Diabetes mellitus/IFG/IGT & 3.55 & $0.81-15.48$ & 0.091 \\
\hline Coronary artery anomaly & 7.90 & $1.10-56.91$ & 0.040 \\
\hline Left main disease & 20.25 & $4.02-101.94$ & 0.0002 \\
\hline SYNTAX score (per 1 pt) & 1.14 & $1.05-1.22$ & 0.001 \\
\hline SYNTAX score $>32$ pts & 40.50 & $7.15-229.41$ & $<0.0001$ \\
\hline Referral for CABG & 10.69 & $2.38-48.15$ & 0.002 \\
\hline Volume of contrast (per $10 \mathrm{~mL}$ ) & 1.08 & $1.01-1.16$ & 0.024 \\
\hline $\begin{array}{l}\text { Volume of contrast to weight } \\
\text { ratio }\end{array}$ & 1.99 & $1.11-3.60$ & 0.022 \\
\hline $\begin{array}{l}\text { Intima media thickness (per } \\
0.1 \mathrm{~mm} \text { ) }\end{array}$ & 1.45 & $1.10-1.92$ & 0.010 \\
\hline $\begin{array}{l}\text { Extra-media thickness (per } \\
0.1 \mathrm{~mm} \text { ) }\end{array}$ & 1.92 & $1.27-2.90$ & 0.002 \\
\hline NSAIDs use & 12.19 & $2.66-55.86$ & 0.001 \\
\hline PSV renal artery (per 1 m/s) & 0.26 & $0.0006-118.81$ & 0.664 \\
\hline EDV renal artery (per $1 \mathrm{~m} / \mathrm{s}$ ) & 0.48 & $0.001-159.16$ & 0.801 \\
\hline RAR & 9.72 & $1.01-93.26$ & 0.049 \\
\hline PSV_-intra-renal (per $1 \mathrm{~m} / \mathrm{s}$ ) & 0.93 & $0.0007-1324.98$ & 0.983 \\
\hline EDV_-intra-renal (per $1 \mathrm{~m} / \mathrm{s}$ ) & $<0.001$ & $<0.00001-10.75$ & 0.095 \\
\hline Renal AT (per $1 \mathrm{~ms}$ ) & 0.99 & $0.96-1.03$ & 0.773 \\
\hline Renal AI (per $\left.1 \mathrm{~m} / \mathrm{s}^{2}\right)$ & 1.22 & $0.68-2.20$ & 0.499 \\
\hline RRI (per 0.01) & 1.16 & $1.03-1.29$ & 0.011 \\
\hline RPI (per 0.01) & 1.04 & $1.00-1.07$ & 0.028 \\
\hline
\end{tabular}

$I F G$ impaired fasting glucose, IGT impaired glucose tolerance, SBP systolic blood pressure, $D B P$ diastolic blood pressure, $R A R$ renal-aortic flow velocity index, $P S V$ peak systolic velocity, $E D V$ end-diastolic velocity, $A T$ acceleration time, $A I$ acceleration index, $A o$ aorta, $V_{\max }$ maximal velocity, $R A R$ renal-aortic flow velocity index, TDI tissue doppler imaging, NSAID non-steroidal anti-inflammatory drugs

may be related to the exclusion of extremely high pulse pressure variables and heart rate, along with the phenomenon of renal blood flow auto-regulation. Therefore, our findings may suggest that RRI delivers additional predictive value on top of the traditional characteristics of arterial stiffness.

Moreover, logistic regression analysis revealed that CIAKI was accurately predicted by morphology of coronary lesions reflected by SYNTAX score, as well as the presence of PAD and DM/IFG/IGT and advanced age. These results underline the significance of vascular pathology and partially comply with former high-volume studies concerning risk factors of CI-AKI $[2,3,6]$. The significance of both SYNTAX score and PAD is probably related with the concomitant renal vascular pathology in patients with more

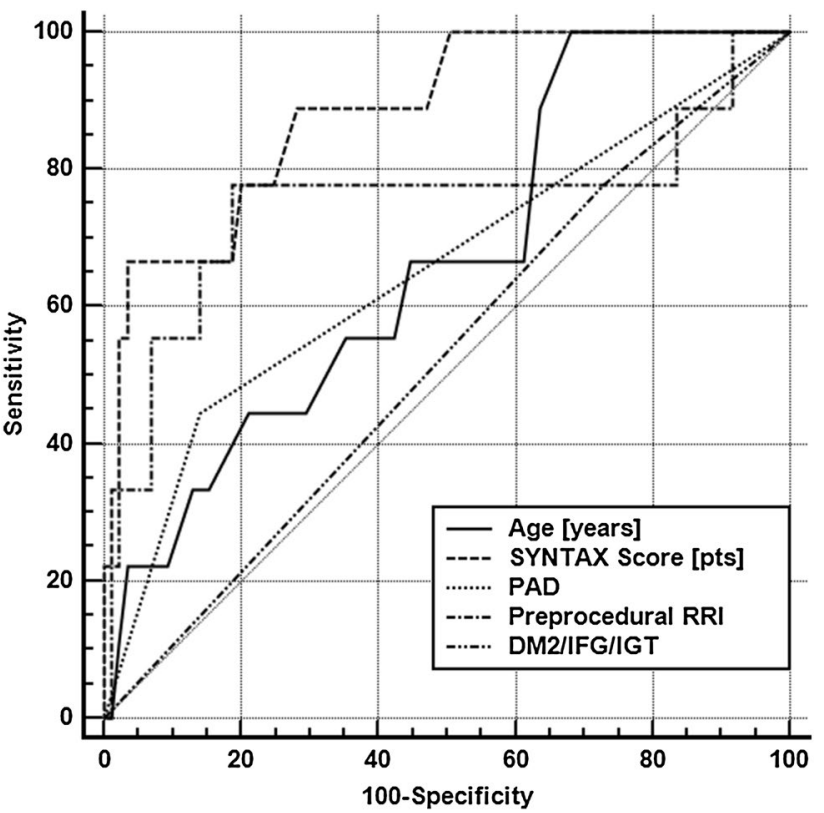

Fig. 1 Receiver operator characteristic curve of the independent predictors of contrast-induced acute kidney injury onset. $D M$ diabetes mellitus, $I F G$ impaired fasting glucose, IGT impaired glucose tolerance, $R R I$ renal resistive index, $P A D$ peripheral artery disease

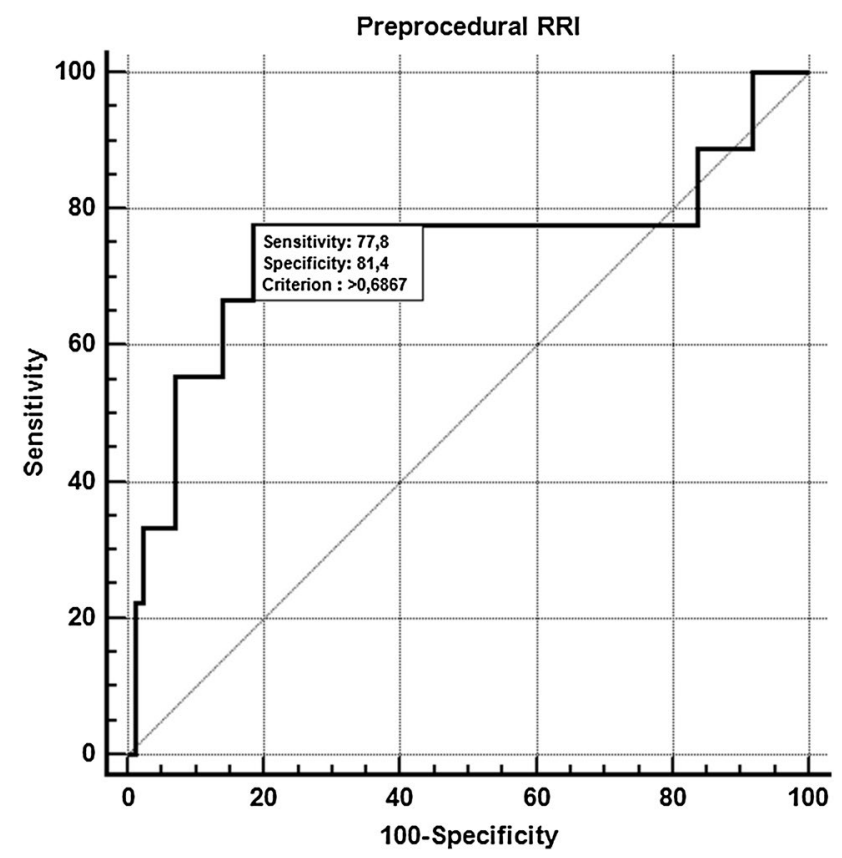

Fig. 2 Receiver operator characteristic curve and threshold for contrast-induced acute kidney injury prediction of pre-procedural renal resistive index. RRI renal resistive index

advanced atherosclerosis, as well as higher requirement for $\mathrm{CM}$ (challenging vascular access site/longer duration of the procedure). 


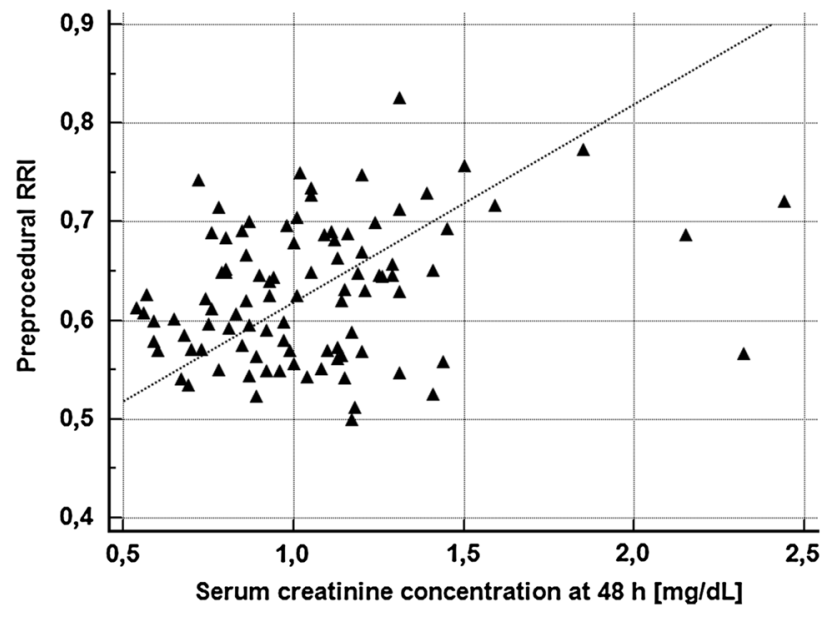

Fig. 3 Correlation between pre-procedural renal resistive index and serum creatinine concentration at $48 \mathrm{~h}$

Also, coronary anomaly, referral for CABG, IMT and EMT value, although not included in the model, were associated with higher risk of renal function worsening based on univariate model (Table 5).

The final predictive model was characterized by a very good diagnostic power for CI-AKI prediction (Fig. 1). The main difference from previous reports was the lack of baseline kidney function and volume of CM in the final model. Still, weight-adjusted total volume of CM was associated with CI-AKI onset based on univariate model ( $\mathrm{OR}=1.99$, $\mathrm{p}=0.022$ ) and was probably excluded from the model because of high collinearity with SYNTAX score. Baseline GFR and creatinine concentration did not predict CI-AKI onset in the described population. This may be explained by the applied exclusion criteria, as the study was designed to select patients with relatively good preliminary kidney function (mean eGFR of $80.7 \mathrm{~mL} / \mathrm{min} / 1.73 \mathrm{~m}^{2}$ ). Only 17 patients were characterized by eGFR between 50 and $60 \mathrm{~mL} / \mathrm{min} / 1.73 \mathrm{~m}^{2}$. Interestingly, these participants had baseline RRI values comparable with the rest of population $(p=0.67)$, suggesting that RRI is rather an indicator of susceptibility to AKI and contrast-mediated renal injury than a marker of impaired kidney function [25].

The results of logistic regression analysis allowed for the identification of patients, who could benefit the most from the pre-procedural screening with renal Doppler ultrasound. Analysis of RRI yields best results in terms of CIAKI assessment in elderly patients with advanced peripheral and coronary atherosclerosis and presence of DM type 2. Based on the results of the study RRI assessment cannot be routinely recommended, yet it is worth consideration in subjects fraught with cardiovascular risk factors, in order to select individuals requiring more intensive peri-procedural hydration regimen with forced diuresis (furosemide preceded by volume expansion) [26], the cessation of possibly nephrotoxic drug (e.g. angiotensin converting enzyme inhibitors) [27], statin loading dose prior to procedure [28], radical limitation of contrast agent dose, as well as careful and prolonged post-procedural renal function monitoring (e.g. $\mathrm{SCr}$ assessment $>72 \mathrm{~h}$ after the procedure).

The main limitation of the study is the imperfection of the renal Doppler ultrasonography itself, as patients with morbid obesity, extreme parameters of pulse pressure and heart rate and renal pathology had to be excluded from the study. Since this method is characterized by rather low repeatability, the RRI and RPI could have varied depending on the current view angle or patient's position. Nevertheless, we have made an effort to overcome this shortcoming by way of using an arithmetic mean of serial measurements in two kidneys. During both pre- and post-procedural examination patients remained in supine position, as the majority of the patients were confined to this position following CA via femoral access. The ideal method should employ the measurement of resistive index by an invasive Doppler flow wire [7], which regrettably was not implemented in our study. Still, this technique may prolong the duration of the procedure and increase $\mathrm{CM}$ use and could trigger renal circulatory complications. Current measurement of RRI should not be applied to high-risk populations with severely impaired renal function, as the manuscript described predominantly low-to-medium CI-AKI risk patients. Due to the fact that last $\mathrm{SCr}$ was assessed at $48 \mathrm{~h}$ after the procedure, the rate of CI-AKI might have been underestimated.

\section{Conclusions}

In the broader perspective, the results of the study underscore the importance of coronary, peripheral and renal vascular pathology in the development of CI-AKI in patients without preexisting renal pathology who are referred for coronary angiography. Pre-procedural evaluation of RRI is a relatively plain diagnostic tool, which independently contributes to risk stratification of CI-AKI.

\section{Compliance with ethical standards}

Conflict of interest The study was financed from the grant for scientific research in the field of cardio-nephrology funded by Adamed Group under the auspices of Polish Society of Cardiology. The authors deny any potential conflict of interests regarding the contents of the article. The authors have full control of all primary data and that they agree to allow the journal to review their data if requested.

Ethical approval The article complies with the 1964 Declaration of Helsinki and its later amendments. All study participants gave their written informed consent for participation in the study. 
Open Access This article is distributed under the terms of the Creative Commons Attribution 4.0 International License (http:// creativecommons.org/licenses/by/4.0/), which permits unrestricted use, distribution, and reproduction in any medium, provided you give appropriate credit to the original author(s) and the source, provide a link to the Creative Commons license, and indicate if changes were made.

\section{References}

1. Rihal CS, Textor SC, Grill DE et al (2002) Incidence and prognostic importance of acute renal failure after percutaneous coronary intervention. Circulation 105:2259-2264

2. Mehran R, Aymong ED, Nikolsky E et al (2004) A simple risk score for prediction of contrast-induced nephropathy after percutaneous coronary intervention: development and initial validation. J Am Coll Cardiol 44:1393-1399

3. Gurm HS, Seth M, Kooiman J, Share D (2013) A novel tool for reliable and accurate prediction of renal complications in patients undergoing percutaneous coronary intervention. J Am Coll Cardiol 61:2242-2248

4. Solomon RJ, Mehran R, Natarajan MK et al (2009) Contrastinduced nephropathy and long-term adverse events: cause and effect? Clin J Am Soc Nephrol 4:1162-1169

5. Vanmassenhove J, Vanholder R, Nagler E, Van Biesen W (2013) Urinary and serum biomarkers for the diagnosis of acute kidney injury: an in-depth review of the literature. Nephrol Dial Transplant 28:254-273

6. Tziakas D, Chalikias G, Stakos D et al (2014) Validation of a new risk score to predict contrast-induced nephropathy after percutaneous coronary intervention. Am J Cardiol 113:1487-1493

7. Kurihara O, Takano M, Uchiyama S et al (2015) Microvascular resistance in response to iodinated contrast media in normal and functionally impaired kidneys. Clin Exp Pharmacol Physiol 42:1245-1250

8. Sendeski M, Patzak A, Persson PB (2010) Constriction of the vasa recta, the vessels supplying the area at risk for acute kidney injury, by four different iodinated contrast media, evaluating ionic, nonionic, monomeric and dimeric agents. Invest Radiol 45:453-457

9. Huang SS, Huang PH, Leu HB, Wu TC, Lin SJ, Chen JW (2013) Association of central pulse pressure with contrast-induced nephropathy and clinical outcomes in patients undergoing coronary intervention. J Hypertens 31:2187-2194

10. Radermacher J, Chavan A, Bleck J et al (2001) Use of Doppler ultrasonography to predict the outcome of therapy for renalartery stenosis. N Engl J Med 344:410-417

11. Winther SO, Thiesson HC, Poulsen LN, Chehri M, Agerskov H, Tepel M (2012) The renal arterial resistive index and stage of chronic kidney disease in patients with renal allograft. PLoS One 7:e51772

12. Ninet S, Schnell D, Dewitte A, Zeni F, Meziani F, Darmon M (2015) Doppler-based renal resistive index for prediction of renal dysfunction reversibility: a systematic review and meta-analysis. J Crit Care 30:629-635
13. Schnell D, Deruddre S, Harrois A et al (2012) Renal resistive index better predicts the occurrence of acute kidney injury than cystatin C. Shock 38:592-597

14. Kuznetsova T, Cauwenberghs N, Knez J et al (2015) Doppler indexes of left ventricular systolic and diastolic flow and central pulse pressure in relation to renal resistive index. Am J Hypertens 28:535-545

15. Pearce JD, Craven TE, Edwards MS et al (2010) Associations between renal duplex parameters and adverse cardiovascular events in the elderly: a prospective cohort study. Am J Kidney Dis 55:281-290

16. Lerolle N (2012) Please don't call me RI anymore; I may not be the one you think I am! Crit Care 16:174

17. Mehta RL, Kellum JA, Shah SV, Acute Kidney Injury Network et al (2007) Acute kidney injury network: report of an initiative to improve outcomes in acute kidney injury. Crit Care 11:R31

18. Seeliger E, Becker K, Ladwig M, Wronski T, Persson PB, Flemming B (2010) Up to 50-fold increase in urine viscosity with isoosmolar contrast media in the rat. Radiology 256:406-414

19. Ribeiro L, de Assunção e Silva F, Kurihara RS, Schor N, Mieko E, Higa $S$ (2004) Evaluation of the nitric oxide production in rat renal artery smooth muscle cells culture exposed to radiocontrast agents. Kidney Int 65:589-596

20. Cantley LG, Spokes K, Clark B, McMahon EG, Carter J, Epstein FH (1993) Role of endothelin and prostaglandins in radiocontrast-induced renal artery constriction. Kidney Int 44:1217-1223

21. Liu ZZ, Schmerbach K, Lu Y et al. (2014) Iodinated contrast media cause direct tubular cell damage, leading to oxidative stress, low nitric oxide, and impairment of tubuloglomerular feedback. Am J Physiol Renal Physiol 306:F864-F872

22. Lerolle N, Guérot E, Faisy C, Bornstain C, Diehl JL, Fagon JY (2006) Renal failure in septic shock: predictive value of Doppler-based renal arterial resistive index. Intensive Care Med 32:1553-1559

23. Tublin ME, Bude RO, Platt JF (2003) Review. The resistive index in renal Doppler sonography: where do we stand? Am J Roentgenol 180:885-892

24. Darmon M, Schortgen F, Leon R et al (2009) Impact of mild hypoxemia on renal function and renal resistive index during mechanical ventilation. Intensive Care Med 35:1031-1038

25. Naesens M, Heylen L, Lerut E et al (2013) Intrarenal resistive index after renal transplantation. N Engl J Med 369:1797-1806

26. Marenzi G, Ferrari C, Marana I et al (2012) Prevention of contrast nephropathy by furosemide with matched hydration: the MYTHOS (induced diuresis with matched hydration compared to standard hydration for contrast induced nephropathy prevention) trial. JACC Cardiovasc Interv 5:90-97

27. Rim MY, Ro H, Kang WC et al (2012) The effect of renin-angiotensin-aldosterone system blockade on contrast-induced acute kidney injury: a propensity-matched study. Am J Kidney Dis 60:576-582

28. Quintavalle C, Fiore D, De Micco F et al (2012) Impact of a high loading dose of atorvastatin on contrast-induced acute kidney injury. Circulation 126:3008-3016 